\title{
On Ethicality of Educational Management
}

\author{
Ying Liu, FuZhou Xiao
}

JiangXi University of Technology

Keywords: Neo-institutional economics; Educational management; Ethicality

\begin{abstract}
Educational management is a social activity. Any social activity cannot be conducted without people's involvement. Everything that involves human being is an ethical thing. Ethic is the basic rule and standard of people's life. As along as there is human being, there exists ethic.
\end{abstract}

\section{Introduction}

Every research activity, no matter it is humanity field, social field or natural field, should have its own range and object of research. Study of ethicality of educational management is to study the special social phenomenon of educational management and ethical characteristic in its activity. Specifying related categories of the study of ethicality of educational management and defining basic categories it involves are considered to be the logical suppositions to carry out this paper. Although ethic is a basic reason, method and law are to adjust people's social life and communication, different nationalities, different faiths and different values have different understandings. In other words, under different cultural traditions and different cultural backgrounds, "ethic" has different connotations. The most obvious difference can be seen from the different interpretations between oriental cultural tradition, represented by China, and western cultural tradition, represented by Ancient Greece and Rome.

\section{Ethicality of Educational Management}

Neo-institutional economics is an "eminent study" in contemporary western economics. Although neo-institutional economics is a school of economics which mainly studies the role of system in economic development, many conclusions that it has significance of enlightenment to human beings' various activities including educational management activity. In the author's point of view, analysis about the role of informal system in management in neo-institutional economics is an important cause for people's treating ethic as pursuit of educational management.

It is known to all that "system civilization" in modern society" achieves unprecedented state. Contemporary management is also mainly operated by rules and regulations. "System", mentioned in neo-institutional economics, is to normalize and manage people's behaviors and rule systems of the interpersonal relationship. It is composed of formal rules, informal rules and rule implementation mechanism, among which ethical and moral rules and standard are included in informal rules and even become the core constitution. Through making rational analysis of "system", neo-institutional economists hold the view that system possesses economic functions including lowering "transaction cost", "promoting cooperative benefit", "stimulating economic effort", overcoming free rider" and “opportunism”, etc. Representatives of neo-institutional economists North and Lewis et al believe that although the formal rules which take property relations as core are powerful, more direct and more effective in stimulating and limiting people's economic activities, it does not mean it is more 
fundamental and more significant than ideological elements such as ethic in nature. Ideological elements such as ethic are not only the base of value to form and establish formal rules, but also provide legitimacy defense and spiritual support for existence and function of formal rules. On this basis, ethic is also an important branch in neo-institutional and old institutional economics. That is to say, ethic possesses the same economic functions as an important part of system. Since management and economy are behaviors and activities of human beings, as far as activities and behaviors of human beings are concerned, management and economy achieve direct uniformity through intermediary of benefit. At the same time, from the perspective of system theory, management is practically a control system, which possesses functions including stimulation, guidance, restraint, organization, cohesion and integration, etc, while above-mentioned vocabularies such as "lowering", "promoting", "stimulating", "overcoming" in economic functions of ethic are what management means. According to the thoughts about economic functions of ethic in neo-institutional economics, it can also be inferred that management functions of ethic include lowering operating cost of social management, promoting social cooperation, stimulating people to be aggressive and work hard and providing individual behavior with constraint force and guiding mechanism, etc. These conclusions in contemporary neo-institutional economics do not only fully verify that ethic has management value and is the pursuit of management, but also offer beneficial and realistic (practical) ideological reference for discussing ethicality of educational management.

From the perspectives of philosophy and ethics, management is an activity and behavior of human beings. Human beings' activities and behaviors are caused and driven by their needs. Human needs refer to people's deficiency and waiting status towards external world and reflects people's independence relationship and characteristics towards the external world. To satisfy their needs, people will surely carry out activity and association, which will form social relation as they develop to a certain degree. In people's social relations, there are cooperation, conflict and opposition between people. To keep the society in certain degree of order, people gradually normalize, immobilize and program their own behaviors and the relationship between people, which forms systems and rules. These systems and rules are practically management means and ways of people, which do not only include management means such as laws and policies, which are manifested as words, but also include cultural power including religion, art, ethic and morality. Just as what many economists point out, system is an entity with value which does not only include a whole set of values about human nature and relationship between people. It can be also said that every system has its own ethical basis or at least its moral meaning. In the meantime, any system requires an ideology to defend it and an individual consciousness to push him to practice them.

\section{Apply Appropriate Incentive Mechanism and Make the Organization Move towards the Right Direction}

Studies of psychology believe that people's motivation is triggered by needs. In the educational management process, if this theory is fully utilized to understand actual needs of everyone and stimulate them, it will yield twice the result with half the effort to lead activity and guide organization to the right direction.

Theoretical Basis of Incentive Mechanism. Incentive mechanism theory does not come out of nothing but has its own solid theoretical basis. At present, theoretical basis that constitutes educational management incentive mechanism mainly is "hierarchy of needs theory" of Maslow and "needs motivation theory of two factors" of Hertzberg. 
Organization is a social group constructed in accordance with certain objective and mode. In order to meet the requirements of self operation, the organization has to be equipped with common objective, common ideal and appropriate organ and system, or it will be in a state of disunity. The task of organizational culture is to strive to create common value system and common code of conduct. Organizational culture is the soul of organization and management. It is a "soft" glutinous reagent that constitutes effectively running internal driving force with intangible "soft constraint" power. Deere and Peterson thought culture is related to organizational values, etiquette and symbol. As for educational management, most of its core problems are social rather than technical. Important points and outstanding features of organizational culture is that it places the development of organization on the basis of people's common values and ethics.

The essence of paying close attention to organizational members' multiple needs and diversified values is to regard people as the objective and care about employees' interest. Long-term development of organization depends on organizational members' hard work, thus what the benefit of organizational members is, how to treat organizational members and what kind of thoughts are applied to treat them should be taken into account when choosing controlled objects. The development of organization is closely linked to the improvement of quality of organizational members. Hence, when choosing control key points, current organizational activities and future development's requirement for cultural quality of organizational members should be measured and should be made comparison with their current actual ability, in order to confirm necessary educational and training measures to improve the quality of personnel. Sufficient trained personnel should be supplied for the organization and opportunity of growth and development be provided for employees through formulation and implementation of personnel development plan. Secondly, attitude of organizational members have an important influence on current and future development of the organization. If the employees' attitude does not conform to the expectation of organization, indulgence is an irresponsible attitude and is in accordance with ethical spirit. Organizational managers should take effective measures to improve their satisfaction degree whether at work or in life to change their attitude. Ethical control concept admits people have the right to pursue multiple benefits and to adopt optimized ways to realize related benefits. It stresses on physiological care, spiritual and mental care of people and abandons people's physical and spiritual sub-health and mentally ill health resulted from realizing organizational benefit. For example, many western developed countries pursue economic development and organizational benefit, making people become instruments of labor and their slaves. More importantly, paying close attention to multiple needs and diversified values in educational management is to "concern with the young generation" through caring about faculty and staff's welfare.

Pursuit of benefit (quality) is the necessity of human's scientific spirit and professional ethics, which is reflected on the appearance of "scientific management theory" in the history of management theory development. "Benefit principle" indicates that the core concept of management is to pursue maximizing the efficiency and the benefit. Performance is a key indicator to measure strength of an organization. Therefore, performance is often regarded as the primary need of management in management activity. However, no organization exists alone. It has to survive in the big system of society. Society is a complex system with many subsystems which depend on each other for existence just like ecosystem. Educational management is a part of the society. It has to learn to get along with each other in peace with other systems rather than ignoring their existence or thinking of using them. Implementation of objective of educational management and pursuit of performance 
require support and cooperation of other aspects in the social environment. Educational managers should aware that performance is absolutely the need of organization and necessity of management, but they cannot only focus on performance and fail to see the wood for trees in the pursuit of performance. In the pursuit of performance, organizers and managers should specify one concept: efficiency is produced by educational management, and productivity is produced by management. Management is an economic behavior, but educational management is a human activity as well. One should take people's happiness as the objective and social value as orientation. Social needs and social benefits are logistics prepositions to carry out educational management and foundation for its rationality and legitimacy. Hence, in the process of pursuing for performance, educational management should pay attention to its social obligation at the cost of releasing its own social obligation. "In the pursuit of self-interest, educational management activity has to attach importance to social benefit, take responsible for the society, or else it will lose its due social value and lose the cause and significance of existence". The least ethical requirement for educational management is not to harm the society, not to touch the benefits of social citizens or not to violate the bottom line of social ethics. On the contrary, it has to possess basic conscience, initiatively cultivate talents for the society, participate in social affairs and earnestly serve for the public welfare establishment and citizens so as to win the public's praise and promote continuous organizational development.

\section{Conclusion}

Amita once said that morality is the foundation for management. When morality and ethics embody and rein management and leadership of school, performance of educational management will greatly surpass people's expectation. It can be seen that conducting educational management by ethical spirit is not only the popular sentiment of China in building a harmonious society, but also the trend of human society moving towards Great Harmony.

Ethic is an inherent property of educational management. Educational management contains pursuit of moral value objectives and ethics stipulation and possesses ethical characteristics. In the practice of educational management and theoretical study, both managers who are engaged in educational management and researchers who are engaged in educational management ignore ethicality should be reflected on educational management. From the level of practice of educational management, it treats people as tools driven by benefit who only lay emphasis on performance, "sees things but not people" and lacks of sufficient attention to people's inner psychology, complicated and changeable values, multiple inner natures and complex social environment. From the level of theoretical study of educational management, there are many works studying educational management, but the least of perfection is that most studies focused on object, functional activity, hierarchical structure and organizational system of educational management. Going through thesis related to educational management, it can be found that few studies regard ethic of educational management as a specialized study object and few relevant contents appeared in books or articles.

This study treats ethicality of educational management as its specialized research object and reveals ethical characteristic of educational management to make up deficiency in previous studies. To put it bluntly, ethicality of educational management to be studied hopes that ethical appeal and ethical characteristic of educational management can be more specified on theoretical level and more operational on practice level. Since the study is relatively strange, tough, narrow and deep in topic selection, few bibliographies can be referred to and limited ability of the author of this paper, deficiencies are unavoidable in this paper, which is mainly reflected on practice token and 
operational interpretation of ethicality of educational management. This paper hopes to attract attention from more responsible scholars and is served as a modest spur. It is believed that with social progress and continuous improvement of quality of educational managers, more and more managers will voluntarily apply ethic to improve themselves and normalize professional behavior, making educational management show more humanistic feelings and ethical implications.

\section{References}

[1] Trevino L K. Moral reasoning and business ethics: Implications for research, education, and management[J]. Journal of Business Ethics, 1992, 11(5-6): 445-459.

[2] Trevino L K. Moral reasoning and business ethics: Implications for research, education, and management[J]. Journal of Business Ethics, 1992, 11(5-6): 445-459.

[3] Matten D, Moon J. Corporate social responsibility education in Europe[J]. Journal of business Ethics, 2004, 54(4): 323-337.

[4] Tsalikis J, Fritzsche D J. Business ethics: A literature review with a focus on marketing ethics[J]. Journal of Business Ethics, 1989, 8(9): 695-743.

[5] Ghoshal S. Bad management theories are destroying good management practices[J]. Academy of Management learning \& education, 2005, 4(1): 75-91.

[6] Cullen J B, Parboteeah K P, Hoegl M. Cross-national differences in managers' willingness to justify ethically suspect behaviors: A test of institutional anomie theory[J]. Academy of Management Journal, 2004, 47(3): 411-421.

[7] Crown D F, Spiller M S. Learning from the literature on collegiate cheating: A review of empirical research[J]. Journal of Business Ethics, 1998, 17(6): 683-700.

[8] McCabe D L, Trevino L K, Butterfield K D. The influence of collegiate and corporate codes of conduct on ethics-related behavior in the workplace[J]. Business Ethics Quarterly, 1996: 461-476.

[9] Dill D D. The management of academic culture: Notes on the management of meaning and social integration[J]. Higher education, 1982, 11(3): 303-320.

[10] Terpstra D E, Rozell E J, Robinson R K. The influence of personality and demographic variables on ethical decisions related to insider trading[J]. The Journal of Psychology, 1993, 127(4): 375-389. 